\title{
Development of blended yarns and fabric using chokla wool and camel hair
}

\author{
Jaya Paliwal, Mamta Agrawal and Bharti
}

Received: 06.04.2018; Revised: 13.10.2018; Accepted: 26.10.2018

See end of the paper for authors' affiliations

Jaya Paliwal

Department of Textiles and Apparel Designing, College of Home Science, S.K. Rajasthan Agriculture University, Bikaner (Rajasthan) India
ABSTRACT : The present study was conducted to investigate the effect of blending camel hair and chokla wool in different ratios and study the properties of fibres, yarn and fabric along with the acceptability of blended fabrics. Camel hair and chokla wool fibres were blended together in the proportion of 25:75, 50:50 and 75:25, respectively. Yarn of 100 per cent wool and camel fibre were also made for base reference. Different properties of blended yarn and fabric were evaluated. The study indicated that fabric sample of camel hair and chokla wool of 50:50 was a good blended fabric which showed good warmth, texture, luster and aesthetic appearance. So, it was concluded that camel hair can be successfully blended with chokla wool. Blending improves certain properties of chokla wool and camel hair.

KEY WORDS: Blending, Yarn count, Fineness, Tenacity

- HOW TO CITE THIS PAPER : Paliwal, Jaya, Agrawal, Mamta and Bharti (2018). Development of blended yarns and fabric using chokla wool and camel hair. Asian J. Home Sci., 13 (2) : 516-519, DOI: 10.15740/HAS/AJHS/13.2/516-519. Copyright@ 2018: Hind Agri-Horticultural Society. 